\title{
Treatment of Hot Wash Liquor using Fly Ash
}

\author{
Selvaraju Sivamani ${ }^{*}$, Mutharasu Kavya ${ }^{2}$, Vignesh Vinusha ${ }^{2}$ \\ ${ }^{1}$ University of Technology and Applied Sciences, Salalah, Oman \\ ${ }^{2}$ Kumaraguru College of Technology, Coimbatore, India \\ *Correspondence: sivman.sel@gmail.com
}

SUBMITTED: 3 December 2021; REVISED: 4 January 2022; ACCEPTED: 7 January 2022

\begin{abstract}
Textile industries are the second largest water-consuming industries, next to agriculture. This research is aimed at investigating the utilization of fly ash as a low-cost adsorbent to treat hot wash liquor by employing one factor at a time. Contact time, effluent dosage, $\mathrm{pH}$, mass of adsorbent, temperature, particle size, and agitation speed have been varied to find the optimum conditions for dye removal from hot wash liquor by fly ash. The results from the sorption process show that the maximum dye removal of $56.07 \%$ has been obtained at a time of $5 \mathrm{~min}$, an effluent to water ratio of 9:1, $\mathrm{pH}$ of 11 , an adsorbent dosage of $0.55 \mathrm{~g} / \mathrm{mL}$, a temperature of $27^{\circ} \mathrm{C}$, a fly ash particle size of $128 \mathrm{~m}$ and an agitation speed of $100 \mathrm{rpm}$. The analysis of the results was performed through adsorption capacity and percentage colour removal. Hence, the results suggested that fly ash could be used as an effective adsorbent for treating dyehouse effluents.
\end{abstract}

KEYWORDS: Adsorption, dyeing, hot wash liquor, fly ash, one-factor-at-a-time

\section{Introduction}

For the past many decades, the textile and dyeing industries have discharged large quantities of synthetic colorants into the environment [1]. Approximately 100,000 dye varieties are commercially available in the world dye market, and most of them are synthetic and highly water soluble. It was reported that about $10 \mathrm{kt}$ of the dyehouse effluent is annually produced through dyeing activities, and approximately $1 \mathrm{kt}$ is released into the aquatic environment with or without proper treatment $[2,3]$. Such discharged dye wastewater would contribute more to the chemical oxygen demand of water bodies. Those dyes are highly carcinogenic, mutagenic, and teratogenic in nature, even in small amounts. Hence, its removal from the aquatic environment becomes mandatory. The removal of dye from wastewater has always been a challenge, as it is very difficult to make the water fit for drinking or other recreational purposes. The majority of the dyes are light and oxidizing agent sensitive [4,5].

Dyehouse effluent could be treated by various chemical, physical, and biological methods. Some processes include adsorption, nanofiltration, colloidal gas aphrons, ultrasonic decomposition, electro coagulation, coagulation and precipitation, advanced chemical oxidation, electrochemical oxidation, photo oxidation, predispersed solvent extraction, ozonation, supported liquid membrane, liquid-liquid extraction, and aerobic and anaerobic biological processes [6,7]. The commonly used techniques, like chemical precipitation, 
biological oxidation, etc., are effective and economic only when solute concentrations are high [8].

Among the unit operations in dyehouse effluent treatment, adsorption occupies a prominent position. Adsorption exploits the ability of certain solids to preferentially concentrate specific substances from solution onto their surfaces [9]. Sorption is a general term introduced by J.W. McBain that includes selective transfer to the surface and into the bulk liquid. In general, in the sorption process, the sorbed solutes are referred to as sorbates, and the sorbing agent is the sorbent. The adsorption process may be classified as a purification or bulk separation depending on the concentration of the feed to the component adsorbed $[10,11]$. Early applications of adsorption involved only purification. For example, adsorption with charred wood to improve the taste of water has been known for at least five centuries. Based on the nature of the bonding between the molecule and the surface, adsorption phenomena can be classified as physisorption and chemisorption. In physical adsorption, the only bonding is weak Vander Waals forces. There is no significant redistribution of electron density in either the molecule or on the substrate surface. In chemisorption, a chemical bond involving substantial rearrangement of electron density is formed between the adsorbate and the substrate. The nature of this bond may be ionic or have a completely covalent character [12,13]. The major objectives of this work are: (i) to characterize fly ash of different sizes to evaluate its potential for dye removal; and (ii) to optimize the removal of dye from hot wash liquor by using a onefactor-at-a-time approach by using highly porous fly ash.

\section{Materials and Methods}

\subsection{Materials}

Sodium hydroxide pellets and sulphuric acid of analar grade are available from SD Fine Chemicals Limited, Mumbai. Hot wash liquor was collected from the State Industries Promotion Corporation of Tamil Nadu (SIPCOT), Perundurai, Erode district, Tamil Nadu, India $\left(11.27^{\circ} \mathrm{N} 77.58^{\circ} \mathrm{E}\right)$. A centrifuge from REMI (Model R8C) was used for the separation of fly ash from dye solution. A Visible spectrophotometer from Systronics (Model Spectrophotometer 106) was used for measuring the absorbance of a solution. A shaker from Scigenics Biotech Private Ltd., Chennai, was used for mixing the samples and fly ash at optimal conditions. A pH meter from Elico (Model LI-120) was used for measuring the $\mathrm{pH}$ of samples.

\subsection{Preparation and characterization of fly ash}

Fly ash is obtained from the first inland station of the Tamil Nadu Generation and Distribution Corporation Limited (TANGEDCO), Mettur thermal power plant, Salem district, Tamil Nadu, India $\left(11.87^{\circ} \mathrm{N} 77.80^{\circ} \mathrm{E}\right)$. The particle size distribution of collected fly ash is found to be between $0.106-2.36 \mathrm{~mm}$. A higher degree of particle size distribution in fly ash is found between 128 and $181 \mathrm{~m}$. The required particle size of fly ash was obtained by sieving in a rotap sieve shaker. The fly ash is used as received without any pretreatment in the adsorption experiments. The fly ash was characterized by bulk density, porosity, and specific gravity before batch experimental studies [14]. 


\subsection{Batch adsorption studies}

The effect of contact time was studied to determine the time taken by the adsorbent to reach equilibrium at fixed conditions of $\mathrm{pH} 13$ (actual $\mathrm{pH}$ of hot wash liquor), the effluent concentration of $100 \%(\mathrm{v} / \mathrm{v})$, the agitation speed of $100 \mathrm{rpm}$, the adsorbent dosage of $0.5 \mathrm{~g} / \mathrm{mL}$ and room temperature.

The time was varied from 5 minutes to 60 minutes. The sample withdrawn was filtered and the concentration was determined. The effect of $\mathrm{pH}$ on the percentage dye removal was studied. The other conditions were fixed at $5 \mathrm{~min}, 100 \%(\mathrm{v} / \mathrm{v}), 100 \mathrm{rpm}$, room temperature, and $0.5 \mathrm{~g} / \mathrm{mL}$. The $\mathrm{pH}$ was varied to $3,5,7,9,11$, and 13 . The concentration of the filtered sample for each $\mathrm{pH}$ was determined.

The concentration of the effluent was varied. The other conditions were $\mathrm{pH} 13$, room temperature, $100 \mathrm{rpm}$, and $0.5 \mathrm{~g} / \mathrm{mL}$. Equilibrium isotherm studies were carried out. The adsorption capacity $(\mathrm{Q})$ and dye removal (DR) were calculated using the following equations:

$$
\begin{aligned}
& \mathrm{Q}=\left(\mathrm{C}_{0}-\mathrm{C}_{\mathrm{f}}\right) * \mathrm{~V} / \mathrm{m} \\
& \mathrm{DR}=\left(\mathrm{C}_{0}-\mathrm{C}_{\mathrm{f}}\right) * 100 / \mathrm{C}_{0}
\end{aligned}
$$

where $\mathrm{Q}$ is adsorption capacity in $\mathrm{mL} / \mathrm{g}, \mathrm{C}_{0}$ is initial dye concentration in $\mathrm{mg} / \mathrm{mL}, \mathrm{C}_{\mathrm{f}}$ is final dye concentration in $\mathrm{mg} / \mathrm{mL}, \mathrm{V}$ is volume of solution in $\mathrm{mL}$, and $\mathrm{m}$ is the mass of adsorbent in g.

The effect of adsorbent dosage was studied to determine the maximum adsorption capacity of the adsorbent. The conditions of $\mathrm{pH} 13$, room temperature, $100 \%(\mathrm{v} / \mathrm{v})$ concentration, and $100 \mathrm{rpm}$ agitation speed were maintained. The experiment was carried out for dosages of $5 \mathrm{~g} / 18 \mathrm{~mL}, 10 \mathrm{~g} / 18 \mathrm{~mL}$, and $15 \mathrm{~g} / 18 \mathrm{~mL}$, and the concentrations of the final solutions were measured. The effect of particle size was studied. The conditions of $\mathrm{pH} 13$, room temperature, $100 \%(\mathrm{v} / \mathrm{v})$ concentration, 100 rpm agitation speed, and $0.5 \mathrm{~g} / \mathrm{mL}$ adsorbent dosage were maintained. The experiment was carried out for average particle sizes of 128 and $181 \mathrm{~m}$, and the concentrations of the final solutions were measured. The effect of agitation speed was studied. The conditions of $\mathrm{pH} 13$, room temperature, $100 \%(\mathrm{v} / \mathrm{v})$ concentration, and $0.5 \mathrm{~g} / \mathrm{mL}$ adsorbent dosage were maintained. The experiment was carried out at speeds of 50, 100 , and $150 \mathrm{rpm}$ and the concentrations of the final solutions were measured. The effect of temperature was carried out to determine the thermodynamics. The conditions of $\mathrm{pH}, 5 \mathrm{~min}$ for time, $100 \%$ for concentration, $10 \mathrm{~g} / 18 \mathrm{~mL}$ for adsorbent dosage, and $100 \mathrm{rpm}$ for speed were maintained. The concentrations of final solutions were determined [16].

\section{Results and Discussion}

\subsection{Characterization of fly ash}

Bulk density is the mass of many particles of a material divided by the total volume they occupy. The bulk density of fly ash with average particle sizes of $128 \mathrm{~m}$ and $181 \mathrm{~m}$ was determined. The bulk density of particles of size $128 \mathrm{~m}$ was found to be $1.74 \mathrm{~g} / \mathrm{mL}$, which is less than that of $181 \mathrm{~m}(2.27 \mathrm{~g} / \mathrm{mL})$. Porosity is a measure of the void spaces in a material and is a fraction of the volume of voids over the total volume. The porosity was determined for 
both particle sizes $(128 \mathrm{~m}$ and $181 \mathrm{~m})$ and was found to be $50 \%$ and $40 \%$, respectively. The higher the porosity, the more effective the adsorption process, so we reduced the fly ash to an average particle size of $128 \mathrm{~m}$ (Table 1).

Specific gravity is the ratio of the density of a substance to the density of a standard, usually water for liquids or solids and air for gas. The specific gravity of fly ash with average particle sizes of $128 \mathrm{~m}$ and $181 \mathrm{~m}$ was determined. The specific gravity of particles with a size of $128 \mathrm{~m}$ was found to be 1.06 , which is less than that of $181 \mathrm{~m}$ (1.65). The results are in line with the data reported elsewhere [17].

Table 1. Characteristics of fly ash

\begin{tabular}{cccc}
\hline \multirow{2}{*}{ S. No. } & \multirow{2}{*}{ Characteristics } & \multicolumn{2}{c}{ Particle size $(\boldsymbol{\mu m})$} \\
\cline { 3 - 4 } & & $\mathbf{1 2 8}$ & $\mathbf{1 8 1}$ \\
\hline 1 & Bulk density $(\mathrm{g} / \mathrm{mL})$ & 1.74 & 2.27 \\
2 & Porosity & 0.5 & 0.4 \\
3 & Specific gravity & 1.06 & 1.65 \\
\hline
\end{tabular}

\subsection{Batch adsorption studies}

The contact time for maximum adsorption was determined in the initial adsorption experiments, which were carried out from $5 \mathrm{~min}$ to $60 \mathrm{~min}$. The maximum adsorption was attained at $5 \mathrm{~min}$ and hence this was used for all further experiments. The maximum dye removal was found to be $50.57 \%$ (Figure 1A). Figure 1B shows that fly ash can appreciably uptake dyes. With increasing dye concentration, the percentage dye removal gets constant and, thereby, the adsorption capacity is linear. The maximum dye removal was found to be $52.4 \%$. The $\mathrm{pH}$ of the effluent is one of the most important parameters affecting the adsorption process. The original $\mathrm{pH}$ of the hot wash liquor was found to be 13 . The maximum amount of dye removal was found to be at $\mathrm{pH} 3$. At a higher $\mathrm{pH}$, the fly ash would have a net positive charge, leading to electrostatic interaction of dye cations. This confirms that there is a clear competition between protons and dye cations for the adsorption sites in the fly ash. The main principle behind this adsorption mechanism is ion exchange. But the optimum $\mathrm{pH}$ was 11 (Figure 1C). Because higher amounts of $0.1 \mathrm{~N} \mathrm{HCl}$ have to be added to bring the $\mathrm{pH}$ of the hot wash to $\mathrm{pH}$ 3 , which is not economically efficient, Hence, the maximum dye removal was found to be $60.41 \%$ at $\mathrm{pH} 11$. Temperature has a strong effect on the adsorption process. As the temperature increases, the solubility of the dye into the hot wash liquor increases, which makes the dye removal by the fly ash decrease. Hence, the maximum dye removal was achieved at room temperature $\left(27^{\circ} \mathrm{C}\right)$.

The highest percentage of dye removal was found to be 58\% (Figure 1D). The amount of fly ash added plays a significant role in the adsorption process. The more the quantity of fly ash is added, the greater the dye removal. In the present investigation, the maximum amount of dye was adsorbed at $0.55 \mathrm{~g} / \mathrm{mL}$ of adsorbent; it decreased before and after this adsorbent dose. Hence, the maximum dye removal obtained was $62.45 \%$ (Figure 1E). The agitation speed does not have a high impact on the adsorption process. From the figure, the optimum speed obtained was $100 \mathrm{rpm}$. At very low speeds, the fly ash and the hot wash do not mix properly, thereby their interaction is very low. Even at very high speeds, there is no proper interaction between the hot wash and the fly ash. Hence, the maximum dye removal percentage was found to be $50.76 \%$ (Figure 1F). The effect of particle size has a significant role in adsorption. The 
smaller the particle size, the greater the surface area of the adsorbent, and thereby greater adsorption. The porosity of the fly ash should be higher. From this experimentation, the maximum removal at the particle size of $128 \mathrm{~m}$ was found to be $53.83 \%$ (Figure $1 \mathrm{G}$ ). The results are in line with the data reported elsewhere [18-20].
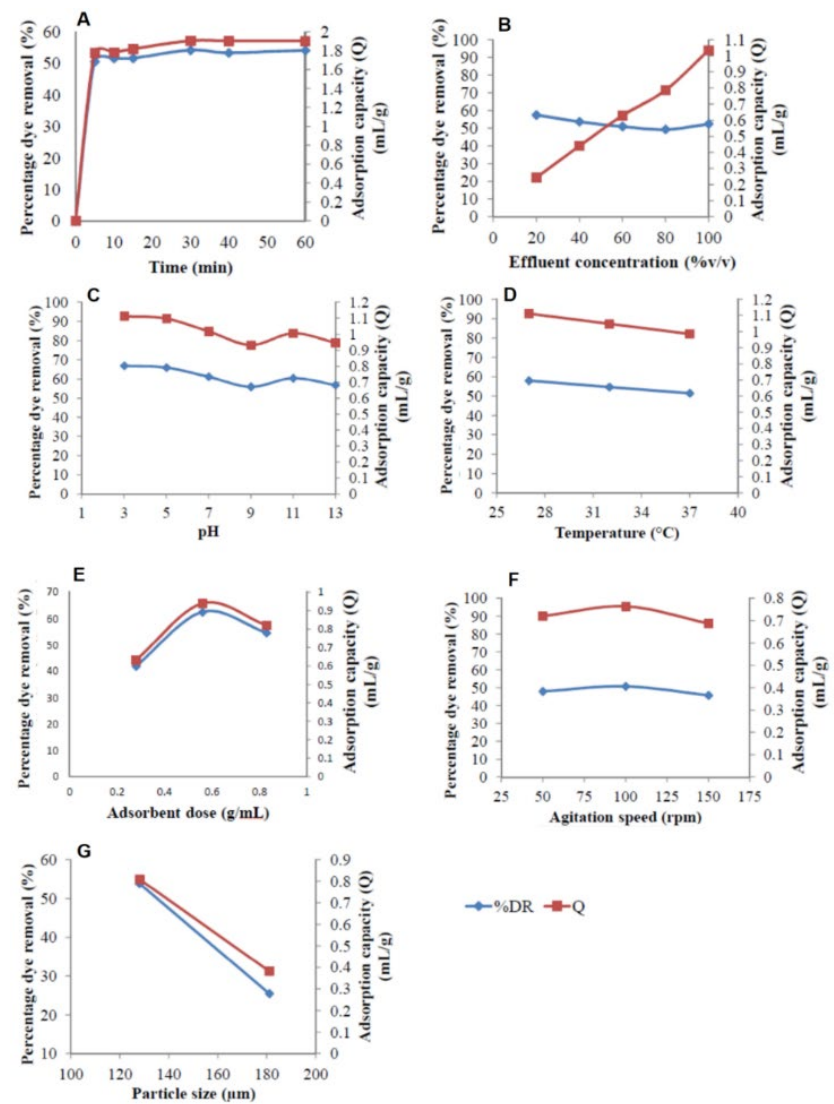

Figure 1. Effect of time (A), effluent concentration (B), $\mathrm{pH}(\mathrm{C})$, temperature (D), adsorbent dose (E), agitation speed $(\mathrm{F})$, and particle size $(\mathrm{G})$ on on hot wash liquor treatment by fly ash.

\section{Conclusions}

This work aimed to study the applicability of fly ash for the treatment of hot wash liquor using a fractional factorial design based on a one-factor-at-a-time (OFAT) approach. The optimal values show that the maximum dye removal of $56.07 \%$ was achieved at $\mathrm{pH}$, temperature, effluent concentration, time, adsorbent dosage, particle size and agitation speed of $11,27^{\circ} \mathrm{C}$, 9:1, $5 \mathrm{~min}, 0.55 \mathrm{~g} / \mathrm{mL}, 128 \mathrm{~m}$ and $100 \mathrm{rpm}$. Thus, the results showed that fly ash could be utilized as a cost-effective adsorbent for the treatment of hot wash liquor.

\section{Acknowledgments}

We would acknowledge our heartfelt thanks to the Management of Kumaraguru College of Technology, Coimbatore, India, for the wonderful opportunity, continuing support and encouragement by providing necessary facilities for executing the research work.

\section{Competing Interest}

All authors declared no competing interest. 


\section{References}

[1] Sivamani, S.; Prasad, B.N.; Nithya, K.; Sivarajasekar, N.; Hosseini-Bandegharaei, A. (2021). Back-propagation neural network: Box-Behnken design modelling for optimization of copper adsorption on orange zest biochar. International Journal of Environmental Science and Technology, 1-16. http://dx.doi.org/10.1007/s13762-021-03411-1.

[2] Sivamani, S.; Manimaran, D.R.; Banupriya, A.; Prathap, N.; Vasu, G.; Kanakasabai, P. (2021). A Comprehensive Review on Liquid-Liquid Extraction Based Systems in Treatment of Textile Wastewater. Indian Journal of Science and Technology, 14, 2646-2662. https://doi.org/10.17485/IJST/v14i33.1076.

[3] Sathish, S.; Prasad, B.S.; Kumar, J.A.; Prabu, D.; Sivamani, S. (2021). Batch and column studies for adsorption of naphthalene from its aqueous solution using nanochitosan/sodium alginate composite. Polymer Bulletin, 1-21. https://doi.org/10.1007/s00289-021-03926-0.

[4] Sowmya, R.; Sivarajasekar, N.; Manimaran, D.R.; Sivamani, S. (2020). Biosurfactant assisted liquid-membrane extraction of methyl-orange from aqueous solutions. AIP Conference Proceedings, 2270, 020008. https://doi.org/10.1063/5.0019525.

[5] Nithya, K.; Sathish, A.; Sivamani, S. (2021). In situ synthesis of mesostructured iron oxide nanoparticles embedded in L. camara: adsorption insights and modeling studies. Biomass Conversion and Biorefinery, 1-12. https://doi.org/10.1007/s13399-021-01764-8.

[6] Navya, A.; Nandhini, S.; Sivamani, S.; Vasu, G.; Sivarajasekar, N.; Hosseini-Bandegharaei, A. (2020). Preparation and characterization of cassava stem biochar for mixed reactive dyes removal from simulated effluent. Desalination and Water Treatment, 189, 440-451. http://dx.doi.org/10.5004/dwt.2020.25635.

[7] Kapoor, R.T.; Sivamani, S. (2021). Exploring the potential of Eucalyptus citriodora biochar against direct red 31 dye and its phytotoxicity assessment. Biomass Conversion and Biorefinery, 1-12. https://doi.org/10.1007/s13399-021-01681-w.

[8] Sivarajasekar, N.; Pradeepika, T.; Sivapriya, S.; Gayathri, V.; Sivamani, S. (2020). Optimization of copper (II) biosorption onto waste Gossypium hirsutum seed microwave-biochar using RSM. AIP Conference Proceedings, 2270, 020007. https://doi.org/10.1063/5.0019524.

[9] Balasubramani, K.; Sivarajasekar, N.; Naushad, M. (2020). Effective adsorption of antidiabetic pharmaceutical (metformin) from aqueous medium using graphene oxide nanoparticles: Equilibrium and statistical modelling. Journal of Molecular Liquids, 301, 112426. https://doi.org/10.1016/j.molliq.2019.112426.

[10] Udayakumar, G. P.; Muthusamy, S.; Selvaganesh, B.; Sivarajasekar, N.; Rambabu, K.; Sivamani, S.; Sivakumar, N.; Prakash Maran, J.; Hosseini-Bandegharaei, A. (2021). Ecofriendly biopolymers and composites: Preparation and their applications in water-treatment. Biotechnology Advances, 52, 107815. https://doi.org/10.1016/j.biotechadv.2021.107815.

[11] Alahabadi, A., Singh, P., Raizada, P., Anastopoulos, I., Sivamani, S., Dotto, G. L., ... HosseiniBandegharaei, A. (2020). Activated carbon from wood wastes for the removal of uranium and thorium ions through modification with mineral acid. Colloids and Surfaces A: Physicochemical and Engineering Aspects, 607, 125516. https://doi.org/10.1016/j.colsurfa.2020.125516.

[12] Rahmani-Sani, A.; Singh, P.; Raizada, P.; Lima, E.C.; Anastopoulos, I.; Giannakoudakis, D.A.; Sivamani, S.; Dontsova, T.A.; Hosseini-Bandegharaei, A. (2020). Use of chicken feather and eggshell to synthesize a novel magnetized activated carbon for sorption of heavy metal ions. Bioresource Technology, 297, 122452. https://doi.org/10.1016/j.biortech.2019.122452.

[13] Siyal, A. A.; Shamsuddin, R.; Low, A.; Hidayat, A. (2020). Adsorption kinetics, isotherms, and thermodynamics of removal of anionic surfactant from aqueous solution using fly ash. Water, Air, \& Soil Pollution, 231, 1-13. https://doi.org/10.1007/s11270-020-04879-2.

[14] Joseph, I.V.; Tosheva, L.; Doyle, A.M. (2020). Simultaneous removal of Cd (II), Co (II), Cu (II), $\mathrm{Pb}$ (II), and $\mathrm{Zn}$ (II) ions from aqueous solutions via adsorption on FAU-type zeolites prepared from coal fly ash. Journal of Environmental Chemical Engineering, 8, 103895. https://doi.org/10.1016/j.jece.2020.103895.

[15] Siyal, A.A.; Shamsuddin, M.R.; Low, A. (2021). Fly ash based geopolymer for the adsorption of cationic and nonionic surfactants from aqueous solution-A feasibility study. Materials Letters, 283, 128758. https://doi.org/10.1016/j.matlet.2020.128758. 
[16] Kobayashi, Y.; Ogata, F.; Nakamura, T.; Kawasaki, N. (2020). Synthesis of novel zeolites produced from fly ash by hydrothermal treatment in alkaline solution and its evaluation as an adsorbent for heavy metal removal. Journal of Environmental Chemical Engineering, 8, 103687. https://doi.org/10.1016/j.jece.2020.103687.

[17] Jawad, A.H.; Abd Malek, N.N.; Abdulhameed, A.S.; Razuan, R. (2020). Synthesis of magnetic chitosan-fly ash/Fe $3 \mathrm{O} 4$ composite for adsorption of reactive orange 16 dye: optimization by Box-Behnken design. Journal of Polymers and the Environment, 28, 1068-1082. https://doi.org/10.1007/s10924-020-01669-z.

[18] Bandura, L.; Panek, R.; Madej, J.; Franus, W. (2021). Synthesis of zeolite-carbon composites using high-carbon fly ash and their adsorption abilities towards petroleum substances. Fuel, 283, 119173. https://doi.org/10.1016/j.fuel.2020.119173.

[19] Zhao, X.; Zhao, H.; Huang, X.; Wang, L.; Liu, F.; Hu, X.; Li, J.; Zhang, G.; Ji, P. (2021). Effect and mechanisms of synthesis conditions on the cadmium adsorption capacity of modified fly ash. $\begin{array}{lllll}\text { Ecotoxicology and Environmental Safety, } & 112550 .\end{array}$ https://doi.org/10.1016/j.ecoenv.2021.112550.

[20] Buema, G.; Harja, M.; Lupu, N.; Chiriac, H.; Forminte, L.; Ciobanu, G.; Bucur, D.; Bucur, R. D. (2021). Adsorption Performance of Modified Fly Ash for Copper Ion Removal from Aqueous Solution. Water, 13, 207. https://doi.org/10.3390/w13020207.

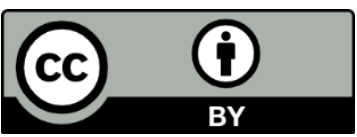

(C) 2022 by the authors. This article is an open access article distributed under the terms and conditions of the Creative Commons Attribution (CC BY) license (http://creativecommons.org/licenses/by/4.0/). 